\title{
NITRATE REDUCTION BY REDOX-MODIFIED SMECTITES EXCHANGED WITH CHITOSAN
}

\author{
Martin Pentrák ${ }^{1,2}$,*, Linda Pentráková ${ }^{1,2}$, Adi Radian ${ }^{3}$, Yael G. Mishael ${ }^{3}$, and Joseph W. Stucki ${ }^{1}$ \\ ${ }^{1}$ University of Illinois at Urbana-Champaign, USA \\ ${ }^{2}$ Institute of Inorganic Chemistry, Slovak Academy of Sciences, Slovakia \\ ${ }^{3}$ Hebrew University of Jerusalem, Israel
}

\begin{abstract}
The presence of nitrate and other redox-active anionic contaminants in terrestrial ecosystems poses a significant risk to humans and other forms of life on Earth. The purpose of the present study was to test a potential in situ system, using poly-(D) glucosamine (chitosan) adsorbed to mineral surfaces under redox-active conditions in order to degrade nitrate to lower oxidation states. Chitosan is a linear polysaccharide derived from the chitin found in the shells of shrimp and other shellfish. Five different loadings of chitosan $(0,0.075,0.25,0.50$, and $1.0 \mathrm{~g} / \mathrm{L}$; labeled $\mathrm{C} 0, \mathrm{C} 1, \mathrm{C} 2, \mathrm{C} 3$, and $\mathrm{C} 4$, respectively) were adsorbed to ferruginous smectite (SWa-1) to form chitosan-SWa-1 composites (CSC) in the $\mathrm{pH}$ range $5.8-4$. The CSC was then reduced by $\mathrm{Na}_{2} \mathrm{~S}_{2} \mathrm{O}_{4}$ in a citrate-bicarbonate buffered dispersion and washed free of excess salts under inert-atmosphere conditions. Upon addition of the nitrate, the solution $\mathrm{pH}$ remained slightly acidic, ranging from 5.5 to 4.7. Samples were analyzed for $\mathrm{Fe}(\mathrm{II})$ content, reacted with a $\mathrm{NaNO}_{3}$ solution, and then re-analyzed for structural Fe(II) content. Supernatant solutions were analyzed for nitrate, nitrite, and ammonium. In samples $\mathrm{C} 1$ to $\mathrm{C} 4$, extensive concentrations of nitrite were observed in the supernatants with a corresponding increase in the reoxidation of structural $\mathrm{Fe}(\mathrm{II})$, proving that a coupled redox reaction had occurred between the nitrate and the structural Fe in the clay mineral. The most efficient loading, defined as the largest percentage of adsorbed nitrate reduced to nitrite, occurred in sample $\mathrm{C} 1$. The total amount of nitrate reduced and $\mathrm{Fe}(\mathrm{II})$ reoxidized followed the trend $0=\mathrm{C} 0<\mathrm{C} 2<\mathrm{C} 3<\mathrm{C} 4 \approx \mathrm{C} 1$. Chitosan showed the potential to reverse the surface charge of constituent clay minerals, thereby enabling the CSC to remove nitrate anions from aqueous mineral systems via redox reactions with structural Fe(II) in clay minerals.
\end{abstract}

Key Words-Clay, Chitosan, FTIR, Iron Reduction, Nanocomposite, Nitrates, Nitrites, Nontronite,

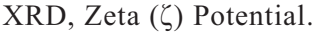

\section{INTRODUCTION}

Nitrates are classified among the most harmful of pollutants in natural waters and soils (Freeze and Cherry, 1979; Bowen et al., 2007; Rabalais, 2002; Camargo and Alonso, 2006; Howarth, 2008), affecting human health (Burow et al., 2010). Nitrate is a highly soluble anion and this greatly enhances the risk of widespread exposure (Thomson, 2001). Nitrates are commonly transported from contaminated water via green plants to the tissues and internal organs of livestock and, thus, to meat consumed by humans.

Once ingested, nitrates accumulate in the body and cause a number of chronic diseases or genetic mutations (Ward et al., 2005). For decades, efforts to devise effective methods for removing nitrates from the human environment and from nature in a way that is highly efficient and acceptable from economic, industrial, and environmental points of view have met with limited success only. Nitrate remediation technologies that have actually been used were recently reviewed by Bhatnagar and Sillanpää (2011), and include zero-valent iron

\footnotetext{
* E-mail address of corresponding author: mpentrak@illinois.edu

DOI: $10.1346 /$ CCMN.2014.0620504
}

( $\mathrm{Fe}(0))$ (Cheng et al., 1997; Sohn et al., 2006; Ahn et al., 2008; Liu et al., 2014) or zero-valent magnesium $(\mathrm{Mg}(0))$ (Kumar and Chakraborty, 2006), ion exchange (Chabani et al., 2006; Samataya et al., 2006), reverse osmosis (Schoeman and Steyn, 2003), electrodialysis (Hell et al., 1998), catalytic denitrification (Pintar et al., 2001), adsorption (Öztürk and Bektaş, 2004; Bhatnagar et al., 2010), and biological denitrification (Soares, 2000).

Natural denitrification processes, including microbial activity, are well known but their efficiency and versatility are still questionable (Seitzinger, 1988; Korom, 1992). Abiotic remediation of saturated zones by reducing agents such as a zero-valent Fe powder or green rust are highly efficient (Huang et al., 1998; Westerhof et al., 2003; Sohn et al., 2006; Hwang et al., 2011). Immense nitrate depletion from Danish soil under anoxic and oxic conditions was reported by Ernstsen (1996) and Ernstsen et al. (1998), who offered a new potential mechanism for nitrate removal from soils. Those authors found that the nitrates were reduced abiotically by structural FeII in the clay minerals, which they proposed to have been created through biotic reduction.

A complex method which couples adsorption, ion exchange, and redox reactions was shown recently to 
reduce nitrate with redox-activated Fe-rich clay minerals, which contain octahedral $\mathrm{Fe}^{3+}$ ( $\mathrm{Su}$ et al., 2012). Iron in ferruginous smectites and nontronites can be reduced chemically or biologically following redox reaction 1 (Stucki et al., 1987, 1988, 1992, 2007; Stucki and Kostka, 2006; Stucki, 2013):

$$
\mathrm{Fe}(\mathrm{III})+\mathrm{e}^{-} \rightarrow \mathrm{Fe}(\mathrm{II})
$$

$\mathrm{Fe}(\mathrm{II})$ is redox active and can react with nitrate according to reaction 2 :

$$
2 \mathrm{Fe}(\mathrm{II})+\mathrm{NO}_{3}^{-}+2 \mathrm{H}^{+} \rightarrow 2 \mathrm{Fe}(\mathrm{III})+\mathrm{NO}_{2}^{-}+\mathrm{H}_{2} \mathrm{O}
$$

where nitrate is reduced to nitrite and ferrous iron is reoxidized back to ferric iron with a $2 \mathrm{e}^{-}$exchange in an acidic environment. This indicates that a promising pathway for nitrate removal is the reaction of nitrate with abiotically reduced structural Fe in clay minerals. A major problem, however, which was documented by $\mathrm{Su}$ et al. (2012), is that the clay mineral surfaces are negatively charged and, thus, repel the nitrate anion. This coulombic repulsion largely prevents natural redox interactions between nitrates and clays. This problem can be circumvented, however, by reversing the charge at the clay mineral surface. This is accomplished by adsorbing an organic polycation onto the smectite, which creates a new, positively charged interface to the surrounding solution. This charge reversal enhances the anion exchange-adsorption capacity (Breen, 1999; Radian and Mishael, 2008; Bleiman and Mishael, 2010; Zadaka et al., 2010; Su et al., 2012). Su et al. (2012) showed that polydiallyldimethylammonium (PDADMAC)-exchanged smectite provided a significant increase in nitrate uptake. This clay-polymer nanocomposite from ferruginous smectite SWa-1 (abbreviated PSC) facilitated extensive interaction with and reduction of nitrate. The optimum PDADMAC loading was $0.25 \mathrm{mg} / \mathrm{g}$ clay. While that study clearly demonstrated that a reaction can occur between reduced-Fe smectites and nitrate, the practicality of such a method has yet to be demonstrated because PDADMAC is a synthetic polycation and does not exist in any significant concentration in nature.

Chitosan (Figure 1) is a biopolymer (linear polysaccharide, poly-(D) glucosamine) derived by $50 \%$ or more de-acetylation of chitin, which is a naturally occurring biopolymer ( $\mathrm{N}$-acetylglucosamine polymer) synthesized by living organisms (shrimp, crabs). This link to a natural substance makes chitosan an appealing

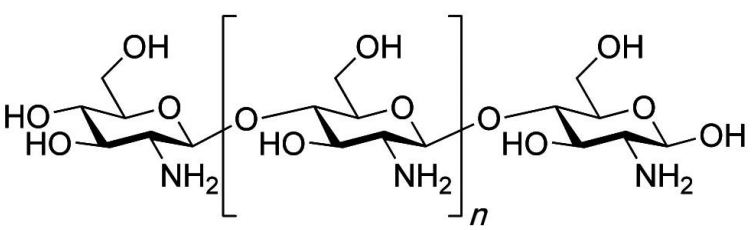

Figure 1. Structure of chitosan, an organic polycation derived from chitin. alternative to more synthetic polycations for reversing the charge on the clay minerals. The solubility of chitosan in aqueous acidic media is high and its functional groups $\left(-\mathrm{NH}_{2},-\mathrm{OH}\right.$, and $\left.-\mathrm{CO}-\right)$ become protonated and able to interact with either negatively or positively charged ions or sites (Rinaudo, 2006). The protonated amino groups are attracted to the negatively charged clay surface by coulombic forces (Bleiman and Mishael, 2010) while also exposing many positively charged groups to the surrounding solution. The chitosan-exchanged smectite composite could be used for many different environmental applications ( $\mathrm{Fu}$ and Qutubuddin, 2001; Dutta et al., 2004; Bhatnagar and Sillanpää, 2009; Monier et al., 2010; Ngah et al., 2011), including the adsorption or sequestration of negatively charged heavy metals and radionuclides (Jeon and Park, 2005; Miretzky and Cirelli, 2009; Bleiman and Mishael, 2010; Dinu and Dragan, 2010; Fu and Wang, 2011; Prakash et al., 2013), inorganic/organic pollutants (Churchman, 2002; Su et al., 2012), and/or dyes (Crini and Badot, 2008; Auta and Hameed, 2014).

The purpose of the present study was to investigate the potential for abiotic redox remediation of nitrate in the natural environment by using a biopolymer, chitosan, prepared from naturally occurring chitin, instead of synthetic PDADMAC for reversing the surface charge of the smectite.

\section{MATERIALS AND METHODS}

\section{Materials}

The smectite used in this study was ferruginous smectite (sample SWa-1, Grant County, Washington, USA, from the Source Clays Repository of The Clay Minerals Society), which was fractionated to $<2 \mu \mathrm{m}$, Nasaturated, and freeze-dried (Na-SWa-1). The unit-cell formula of this mineral was reported by Manceau et al. (2000). The chemicals used were analytical-reagent grade from Thermo Fisher Scientific (Chicago, Illinois, USA), except sodium dithionite powder was only available in technical grade. Chitosan with average molecular weight of 100,000-300,000 Da was obtained from Acros Organics, a division of Thermo Fisher Scientific (Pittsburgh, Pennsylvania, USA).

\section{Methods}

Five different loadings of chitosan with $\mathrm{Na}-\mathrm{SWa}-1$ were prepared as described below. The structural Fe in the clay mineral was then reduced using citratebicarbonate (C-B)-buffered sodium dithionite at $70^{\circ} \mathrm{C}$ for $4 \mathrm{~h}$ (Su et al., 2012). (The C-B solution was prepared by combining $1.0 \mathrm{M}$ sodium bicarbonate and $0.9 \mathrm{M}$ sodium citrate dihydrate at a v/v ratio of 24:1.) Materials prepared in this way were reacted with sodium nitrate solution and the resulting solutions were analyzed for nitrate, nitrite, and ammonium, and the structural Fe(II) content was measured, all using the methods of $\mathrm{Su}$ et al. 
(2012). These oxygen-sensitive samples were handled or stored under an oxygen-free environment as described in detail by Pentrák et al. (2013) and Stucki et al. (2014).

Preparation of CSC. A $1 \mathrm{~g}$ portion of the freeze-dried NaSWa-1 was added to a $50 \mathrm{~mL}$ polycarbonate centrifuge tube (septum-sealable reaction tube described by Pentrák et al., 2013; and Stucki et al., 2014) and dispersed in $200 \mathrm{~mL}$ of deionized water (DI) (18 MOhm-cm resistivity) water to make a $5 \mathrm{~g} / \mathrm{L}$ dispersion. A $3 \mathrm{~g} / \mathrm{L}$ chitosan stock solution was prepared by dissolving $0.75 \mathrm{~g}$ of chitosan powder in $250 \mathrm{~mL}$ of $2 \% \mathrm{v} / \mathrm{v}$ acetic acid (Bleiman and Mishael, 2010). Aliquots from the chitosan stock solution were then combined with a sample of the smectite dispersion to achieve chitosan loadings of 0 , $0.075,0.25,0.5$, or $1.0 \mathrm{~g} / \mathrm{L}$. The chitosan solution was acidic with a $\mathrm{pH}$ of $\sim 3$ and the resulting composites in solution were also slightly acidic ranging from 5.8 (least chitosan loading) to 4 (highest chitosan loading), and the amino groups remained protonated (Bleiman and Mishael, 2010). Each of these mixtures was shaken for $2 \mathrm{~h}$ to achieve maximum dispersion, centrifuged, and the supernatant discarded (Table 1). The remaining solids were labeled $\mathrm{C} 0, \mathrm{C} 1, \mathrm{C} 2, \mathrm{C} 3$, and $\mathrm{C} 4$, respectively.

Characterization of CSC. The composites prepared were characterized by zeta $(\zeta)$ potential measurements, X-ray diffraction (XRD) analysis, and Fourier-transform infrared spectroscopy (FTIR). The $\zeta$ potential and XRD methods were described by Zadaka et al. (2010) and $\mathrm{Su}$ et al. (2012), respectively. The FTIR spectra in the middle infrared (MIR) region $\left(4000-400 \mathrm{~cm}^{-1}\right)$ and in the near infrared (NIR) region $\left(12000-4000 \mathrm{~cm}^{-1}\right)$ were recorded in transmission and reflectance modes, respectively, using a Nicolet 6700 FTIR spectrometer from Thermo-Fisher Scientific (Madison, Wisconsin, USA). For the MIR region, 128 scans and a DTGS detector were used to analyze samples prepared as $\mathrm{KBr}$ pellets ( $1 \mathrm{mg}$ of the sample powder, $200 \mathrm{mg} \mathrm{KBr}$ ) pressed up to $670 \mathrm{MPa}$ and heated overnight at $150^{\circ} \mathrm{C}$ to minimize water content in the sample and $\mathrm{KBr}$. For the NIR region, sample powders were placed directly in the cup of a Smart Diffuse Reflectance Accessory. The raw spectra of both regions were processed using the Thermo Scientific OMNIC ${ }^{\mathrm{TM}}$ software package.

Chemical reduction of structural Fe in CSC. The centrifuged CSC solid was re-suspended in $20 \mathrm{~mL}$ of DI water and then $10 \mathrm{~mL}$ of the C-B buffer was added. The reaction tube was closed using the septum cap, preheated in a water bath to $70^{\circ} \mathrm{C}$, and held for $1 \mathrm{~h}$, all while purging with $\mathrm{O}_{2}$-free $\mathrm{Ar}$ ( $\mathrm{Su}$ et al., 2012). The septum cap was removed, $200 \mathrm{mg}$ of sodium dithionite powder was added, the cap was reinstalled, and the $\mathrm{O}_{2}$ free Ar purge was re-established. After $4 \mathrm{~h}$ at $70^{\circ} \mathrm{C}$, the reaction mixture was removed from the bath and allowed to cool for $1 \mathrm{~h}$. The cooled mixture was disconnected

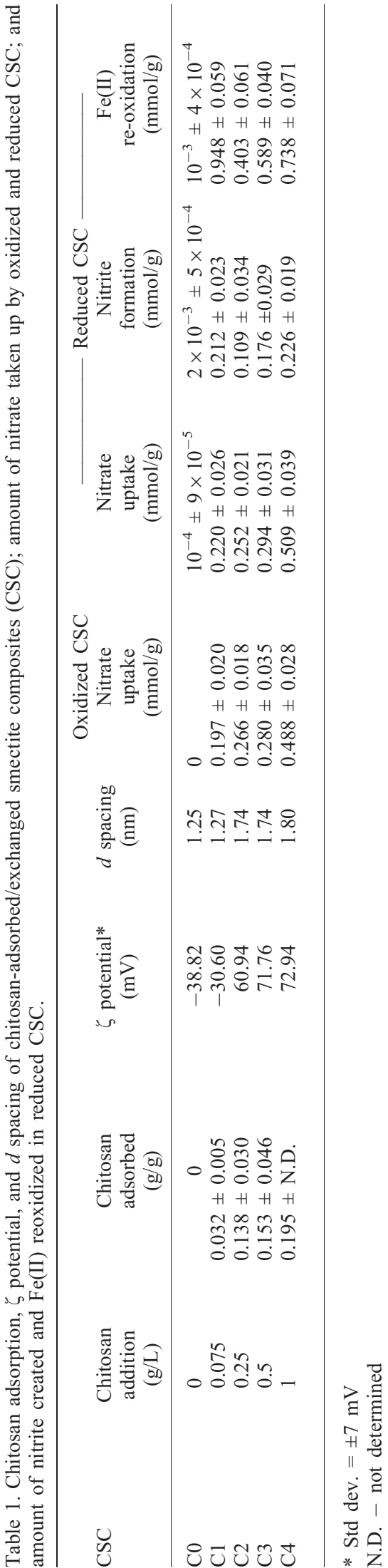


from the purge gas and centrifuged at $5000 \times g$ for 15 min. Using a controlled-atmosphere liquid exchanger (CALE) (Pentrák et al., 2013; Stucki et al., 2014), the reduced $\mathrm{CSC}$ was washed once with deoxygenated $1 \mathrm{M}$ $\mathrm{NaCl}$ and three times with deoxygenated $0.005 \mathrm{M} \mathrm{NaCl}$.

Nitrate reaction with oxidized and reduced CSC. The reaction tube with washed and centrifuged CSC was weighed before and after the addition of $\sim 30 \mathrm{~mL}$ of $0.001 \mathrm{M} \mathrm{NaNO}_{3}$; the precise mass of nitrate added to the CSC was then calculated from the weight of solution added by assuming a liquid density of $1.00 \mathrm{~g} / \mathrm{cm}^{3}$. The CSC was re-suspended into the solution by vortex mixing and allowed to react with the $\mathrm{NaNO}_{3}$ while shaking overnight. The reacted mixture was centrifuged and the supernatant (reacted solution) decanted into an empty, septum-sealed reaction tube under an $\mathrm{O}_{2}$-free $\mathrm{Ar}$ atmosphere, using the CALE apparatus, and stored in the glove box under an Ar atmosphere until analyzed for $\mathrm{N}$ speciation (see below). The reaction tube containing the CSC was also stored in the glove box until analyzed for the $\mathrm{Fe}(\mathrm{II}) /$ total Fe ratio (see below).

Nitrogen and $\mathrm{Fe}$ oxidation-state analysis. The supernatant from the $\mathrm{CSC}-\mathrm{NaNO}_{3}$ reaction mixture was analyzed by the accelerated diffusion method of Khan et al. (1997) and Mulvaney et al. (1997), as adapted by $\mathrm{Su}$ et al. (2012), to determine $\mathrm{NH}_{4}^{+}-\mathrm{N}, \mathrm{NO}_{3}^{-}-\mathrm{N}$, and $\left(\mathrm{NO}_{3}^{-}\right.$ $+\mathrm{NO}_{2}^{-}$)-N. The amount of structural $\mathrm{Fe}(\mathrm{II})$ in the CSC that was reoxidized to $\mathrm{Fe}(\mathrm{III})$ by the nitrate was also measured by submitting the reacted gel to the 1,10-phenanthroline/UV-Vis method (Komadel and Stucki, 1988). Fe(II):total Fe ratios were also confirmed by Mössbauer spectroscopy at $77 \mathrm{~K}$ using a Webb Research, Inc. (Edina, Minnesota, USA) spectrometer equipped with a Janis Model SHE-850-5 closed-cycle cryostat and operating in triangular waveform mode with ${ }^{57} \mathrm{Co}$ source. Spectra were calibrated with respect to a $7 \mu \mathrm{m} \alpha-\mathrm{Fe}$ foil.

\section{RESULTS AND DISCUSSION}

\section{Characterization of CSC}

$\zeta$ potential. The $\zeta$ potential or effective surface charge of the smectite became increasingly more positive compared to CSC sample $\mathrm{C} 0$ as the loading of the chitosan polymer increased (Figure 2) in the sample order $\mathrm{C} 1<$ $\mathrm{C} 2<\mathrm{C} 3<\mathrm{C} 4$; loadings of $0.25 \mathrm{~g} / \mathrm{g}$ and above (samples $\mathrm{C} 2$ to $\mathrm{C} 4)$ produced a net positive charge overall. The attractive force for nitrate adsorption or exchange increased in all cases, in the same sample order.

The $\zeta$ potential of the Na-SWa-1 with no chitosan added (sample $\mathrm{C} 0$ ) was $-38.82 \mathrm{mV}$ and with the highest chitosan loading (sample C4) was $+72.94 \mathrm{mV}$ (Table 1), which represents an overall change in surface charge of $+111.76 \mathrm{mV}$. A similar trend was observed in the previous study (Su et al., 2012) in which PDADMAC was the polycation and the change in surface charge was $+95.82 \mathrm{mV}$. The effect of chitosan on the surface charge was, thus, comparable with PDACMAC. This trend not only follows the extent of chitosan loading, but also the extent of chitosan adsorption on the clay surface, which reached a maximum of $0.195 \mathrm{~g} / \mathrm{g}$ of smectite (Figure 2).

\section{$X$-ray diffraction}

Chitosan intercalation into the clay mineral was characterized by means of XRD measurements (Table 1). A sharp (step-function) increase in $d$ spacing was observed with the adsorption of $0.14 \mathrm{~g}$ polymer $/ \mathrm{g}$ clay and remained constant up to a loading of $0.195 \mathrm{~g}$ polymer/g clay $(\mathrm{C} 0 \approx \mathrm{C} 1<<\mathrm{C} 2=\mathrm{C} 3 \approx \mathrm{C} 4)$. The basal $d$ spacing in montmorillonite (Mnt) (with one layer of entrapped water molecules) is known to be $\sim 1.25 \mathrm{~nm}$ (Usuki et al., 1993; Darder et al., 2005; Radian and Mishael, 2008); with polymer loading this increased to $\sim 1.8 \mathrm{~nm}$, indicating intercalation between the clay layers (Figure 3). Previous experiments have shown that basal spacing of chitosan in SWy-2 increased in two steps; at low loading to $1.46 \mathrm{~nm}$ (corresponding to one polymer chain entering the layers) and at higher loading to 2.18 $\mathrm{nm}$ (corresponding to two polymer chains entering the layers) (Darder et al., 2005; Bleiman and Mishael, 2010). In the present case, only one significant increase was observed, which may indicate that only one polymer layer intercalates (perhaps hydrated due to the larger $d$ spacing) within the SWa-1. This means that partial exfoliation does not occur and surface area may not increase significantly.

\section{Fourier transform infrared spectroscopy (FTIR)}

MIR region. The XRD results were confirmed by FTIR spectroscopy. The MIR spectrum (Figure 4) of sample C0 (Na-SWa-1) contained the typical stretching $(v)$ and bending $(\delta)$ vibrations of $\mathrm{OH}$ and $\mathrm{Si}-\mathrm{O}$ groups common for Fe-bearing smectites, as well as $\mathrm{OH}$ vibrations of

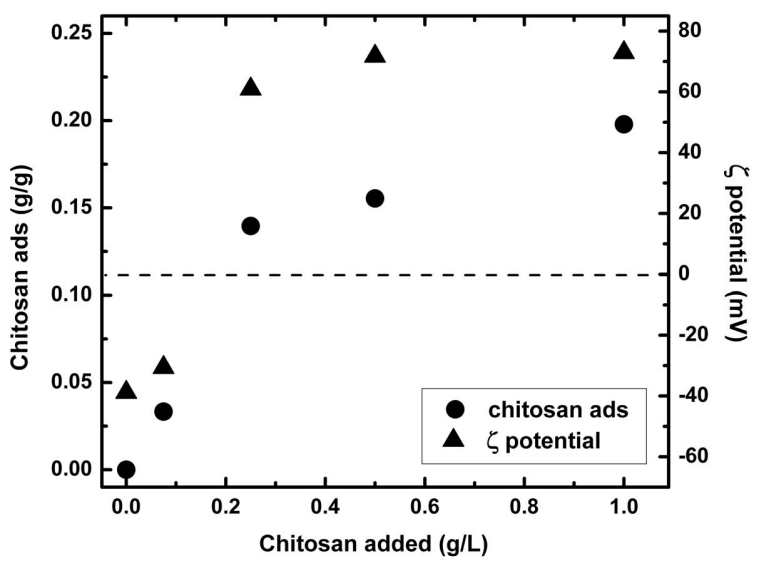

Figure 2. Effect of chitosan loading on its adsorption (ads) to $\mathrm{CSC}$ and the resulting $\zeta$ potential. 


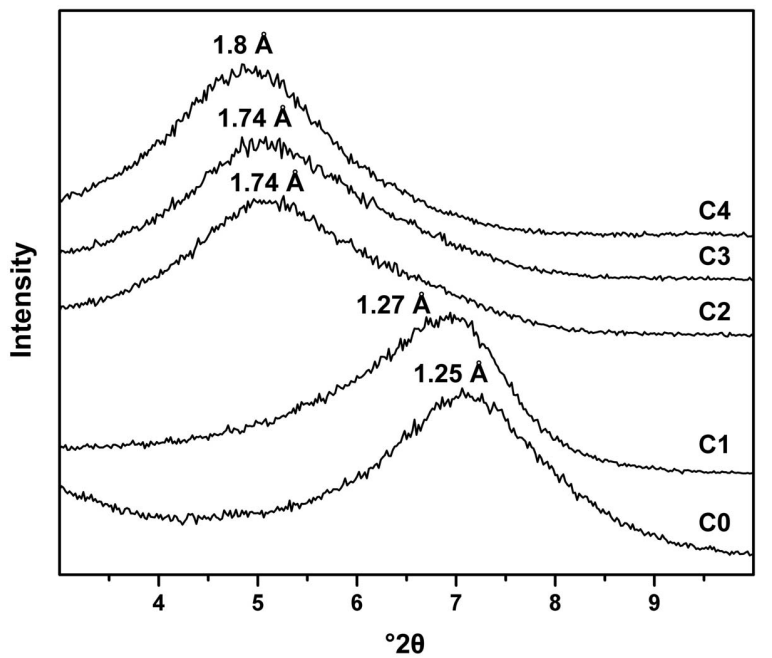

Figure 3. Oriented XRD patterns of Na-SWa-1 (C0) and CSC samples (C1, C2, C3, and C4).

water molecules adsorbed on the smectite surface and water associated with exchangeable cations in the interlayer space (Farmer, 1974; Yan and Stucki, 2000; Madejová and Komadel, 2001; Bishop et al., 2002; Frost et al., 2002; Madejová, 2003). Because the $\mathrm{KBr}$ pellets were heated overnight, the water content was somewhat attenuated (Pentrák et al., 2012). The intensities of both water bands (at $\sim 3400$ and $\sim 1630 \mathrm{~cm}^{-1}$ ) depend critically on the surrounding atmosphere (Yan et al., 1996; Brtáňová et al., 2012; Pentrák et al., 2012) or on the type of intercalated organic or inorganic material
(Czímerová et al., 2004; Pálková et al., 2009; Madejová et al., 2011; Brtáňová et al., 2012, 2014).

Vibrational modes from functional groups of the chitosan included: a broadened band near $3350 \mathrm{~cm}^{-1}$ (Figure 4), attributed to $\mathrm{OH}$ and $\mathrm{NH}$ stretching vibrations; aliphatic C-H stretching bands at $2923 \mathrm{~cm}^{-1}$ and $2883 \mathrm{~cm}^{-1}$ (Madejová et al., 2009b, 2011); carbonyl stretching modes of secondary amides at $1654 \mathrm{~cm}^{-1}$; and bending modes of the amide $(\mathrm{N}-\mathrm{H})$ group near $1597 \mathrm{~cm}^{-1}$ (Brugnerotto et al. 2001). A group of bending vibrations of $\mathrm{C}-\mathrm{H}$ associated with amide and C-C skeletal groups were clearly recognizable in the chitosan spectrum at $1419 \mathrm{~cm}^{-1}$ and $1380 \mathrm{~cm}^{-1}$, respectively (Figure 4). Further, the stretching vibrations at $1320 \mathrm{~cm}^{-1}, 1071 \mathrm{~cm}^{-1}$, and $1030 \mathrm{~cm}^{-1}$ belong to coupled $v(\mathrm{C}-\mathrm{O}-\mathrm{N})$ and $v(-\mathrm{C}-\mathrm{O})$ modes, and the bands at $1321 \mathrm{~cm}^{-1}$ and $1261 \mathrm{~cm}^{-1}$ represent symmetric stretching vibrations of $\mathrm{CH}_{3}$ groups of tertiary amide and $\mathrm{v}(\mathrm{C}$ O-H), respectively (Paulino et al., 2006; Abugoch et al., 2011). Bonds associated with the glycosidic ring provided two sharp bands at $1153 \mathrm{~cm}^{-1}$ and $896 \mathrm{~cm}^{-1}$ (Mucha and Pawlak, 2002).

The FTIR patterns for CSC samples $\mathrm{C} 1-\mathrm{C} 4$ clearly are combinations of the spectra for the unaltered SWa-1 and the pure chitosan. These results offer clear evidence of chitosan adsorption to and/or exchange in the smectite, supported by the changes in XRD $d$ spacings described above, which indicated the insertion of chitosan into the interlayer space (Table 1). The spectrum for sample $\mathrm{C} 1$ was only slightly affected by the presence of chitosan due to the very small amount of

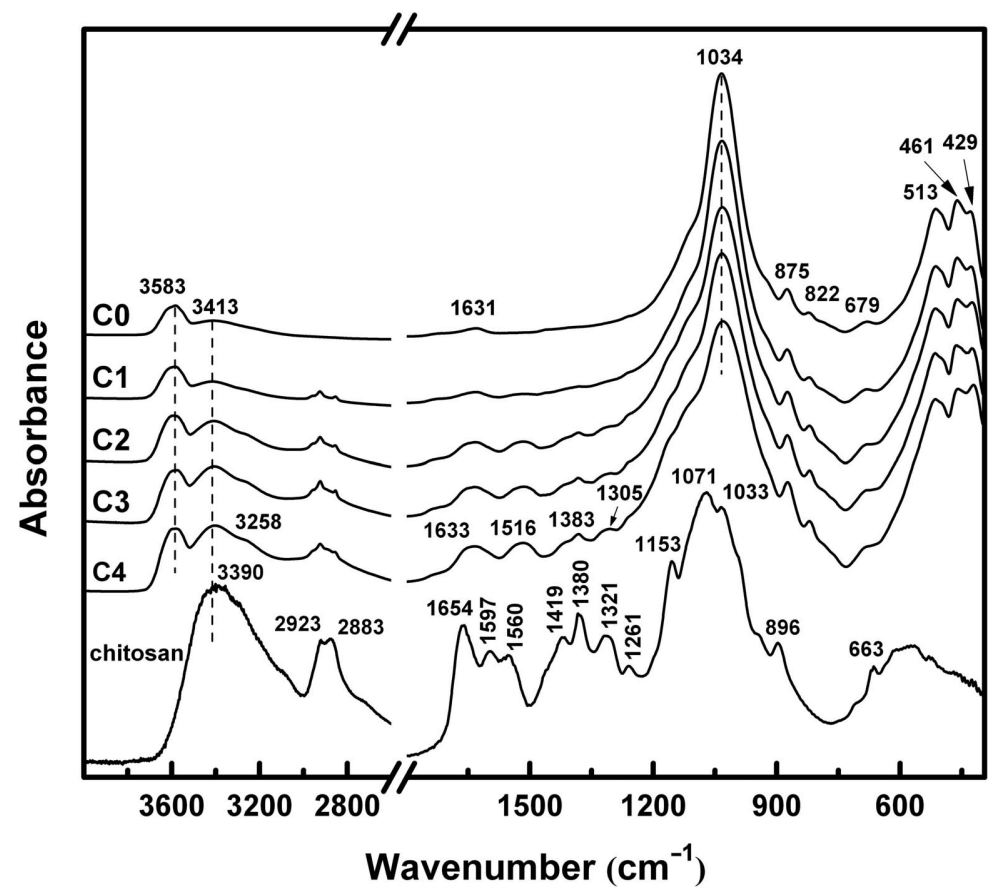

Figure 4. MIR spectra of Na-SWa-1 (C0), CSC samples (C1, C2, C3, and C4), and chitosan alone. 
chitosan (0.032 g/g of clay; Table 1). Bands arising from chitosan were much more prominent in the spectra of samples C2 (0.138 g chitosan/g of clay), C3 (0.153 g chitosan/g of clay), and C4 (0.195 g chitosan/g of clay), which increased in intensity as the amount of chitosan loading increased. This conclusion was further supported by broadened bands at $3406 \mathrm{~cm}^{-1}$ and $3258 \mathrm{~cm}^{-1}$, resulting from the coupled $\mathrm{OH}$ stretching vibrations of chitosan and water molecules. Not surprisingly, $\mathrm{CH}_{2}$ stretching vibrations occurred in the $3000 \mathrm{~cm}^{-1}-$ $2800 \mathrm{~cm}^{-1}$ region (Madejová et al., 2009b, 2011; Pálková et al., 2011) and $\mathrm{CH}_{2}$ bending vibrations near $1320 \mathrm{~cm}^{-1}$ attributed to the pyranose ring of the chitosan structure (Pawlak and Mucha, 2003). Another piece of evidence for the presence of chitosan in the CSC arises from the intense and broadened band at $1633 \mathrm{~cm}^{-1}$, which includes, in addition to the bending mode of water molecules, vibrations from carbonyl $\left(\sim 1700 \mathrm{~cm}^{-1}\right)$ and $\mathrm{C}=\mathrm{O}$ in amide $\left(\sim 1660 \mathrm{~cm}^{-1}\right)$, respectively (Osman and Arof, 2003). Bending modes from -NH- amide and $-\mathrm{NH}_{2}$ amine groups were observed near $1516 \mathrm{~cm}^{-1}$, while bending modes from $\mathrm{OH}$ and $\mathrm{CH}$ in the ring had maxima at $1415 \mathrm{~cm}^{-1}, 1305 \mathrm{~cm}^{-1}$, and $1338 \mathrm{~cm}^{-1}\left(\mathrm{CH}_{3}\right.$ in amide group) (Paulino et al., 2006). On the other hand, a prominent shoulder appeared in the $1200 \mathrm{~cm}^{-1}$ $1050 \mathrm{~cm}^{-1}$ region due to $-\mathrm{C}-\mathrm{O}-\mathrm{C}$ - vibrations in glycosidic linkages (Madejová et al., 2009b; Bleiman and Mishael, 2010; Kumirska et al., 2010; Su et al., 2012). The rising chitosan content was also marked by the reversal of the relative peak intensity ratio of the deformation bands for $\mathrm{Fe}-\mathrm{O}-\mathrm{Si}$ and $\mathrm{Si}-\mathrm{O}-\mathrm{Si}$ at $461 \mathrm{~cm}^{-1}$ and $429 \mathrm{~cm}^{-1}$, respectively.

NIR region. The NIR spectrum of sample $\mathrm{C} 0$ contained overtones and combination vibrations of $\mathrm{OH}$ groups. A complex band at $7062 \mathrm{~cm}^{-1}$ was composed of the first overtone of the smectite structural $\mathrm{OH}$ groups $(2 \mathrm{vOH})$ and the first overtone of the stretching vibrations of water molecules (Figure 5, C0). The combination vibrations of $\mathrm{AlFeOH}$ and $\mathrm{FeFeOH}$ were found at $4468 \mathrm{~cm}^{-1}$ and $4366 \mathrm{~cm}^{-1}$, respectively (Madejová et al., 2009a).

The rising chitosan content in the samples from $\mathrm{C} 0$ to C4 (Figure 5) was reflected in the NIR spectra with a similar trend to that observed in the MIR region (Figure 4). In the $\mathrm{OH}$ overtone region, chitosan $\mathrm{OH}$ groups influenced the final shape and position of the $\mathrm{OH}$ bands, which caused a small shift from $7062 \mathrm{~cm}^{-1}$ (Figure 5, C0) to $7040 \mathrm{~cm}^{-1}$ (Figure 5, C4). The intensity of these $\mathrm{OH}$ bands decreased in the order $\mathrm{C} 0>\mathrm{C} 1>\mathrm{C} 2>$ $\mathrm{C} 3>\mathrm{C} 4$, indicating a lower degree of hydration as the chitosan content increased. Lower hydration was also reflected in the considerable loss of intensity in the band at $5248 \mathrm{~cm}^{-1}$ (combination vibration of water molecules $\left.(v+\delta)_{\mathrm{H}_{2} \mathrm{O}}\right)$. A slight shift of this band to $5235 \mathrm{~cm}^{-1}$ also indicated a weakening in the bonding of water molecules to the composite structures. This occurrence could be explained as a weakening in the strength of $\mathrm{H}$-bonds between water molecules and the basal oxygen atoms and the exchanged $\mathrm{Na}^{+}$cations as the polymer content in the composites increased (Xue et al., 2007; Madejová et al.,

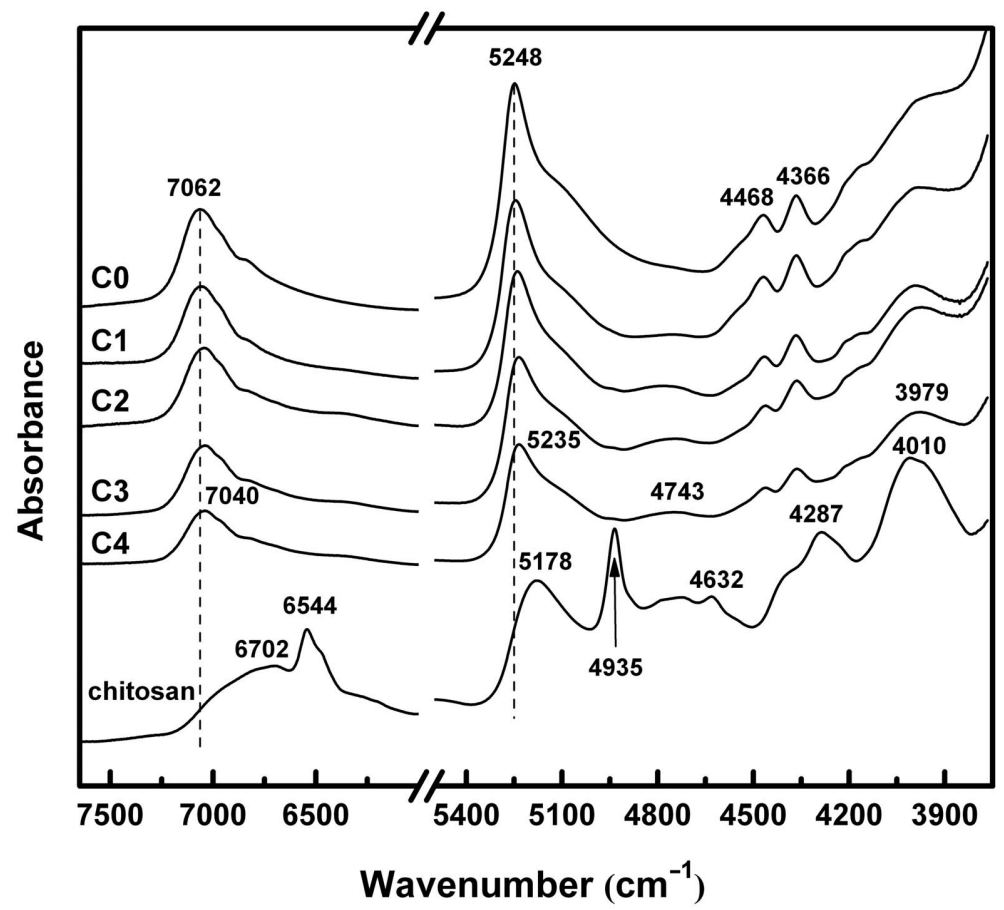

Figure 5. NIR spectra of Na-SWa-1 (C0), CSC samples (C1, C2, C3, and C4), and chitosan alone. 
2011). The presence of a slight progressive growth of combination bands from the $\mathrm{NH}$ and $\mathrm{CH}$ groups of chitosan in the $5000 \mathrm{~cm}^{-1}$ to $4600 \mathrm{~cm}^{-1}$ and in the $4500 \mathrm{~cm}^{-1}$ to $4000 \mathrm{~cm}^{-1}$ regions (Madejová et al., 2009b, 2011) was also further evidence for increasing chitosan content in the composites (Figure 5).

\section{Oxidized CSC reaction with $\mathrm{NO}_{3}^{-}$}

The extent and type (adsorption vs. redox) of reaction between nitrate and oxidized CSC samples were measured by monitoring the amount of nitrate, nitrite, and ammonium in solution after completion of the reaction. Neither ammonium nor nitrite was detected. The amount of nitrate removed from solution by the oxidized CSC increased with increasing loading of chitosan into the smectite (Figure 6), as would be expected due to the increasingly more positive $\zeta$ potential. The amounts ranged from 0 in sample $\mathrm{C} 0$ to $0.5 \mathrm{mmol} / \mathrm{g}$ in sample C4 (Table 1). All of the nitrate lost from solution in this case was assumed to be adsorbed to the CSC because no redox reaction was possible between structural $\mathrm{Fe}(\mathrm{III})$ and $\mathrm{NO}_{3}^{-}$. This outcome was consistent with the earlier finding of $\mathrm{Su}$ et al. (2012) using a different polycation (PDADMAC) for charge reversal. In that study, nitrate attraction to the surface also increased with polycation loading.

Sample C1 presented an interesting phenomenon. In spite of having a negative $\zeta$ potential of $-30.6 \mathrm{mV}$, nitrate was still attracted to it. The reason for this must be because, even though the entire negative charge on the smectite had not been neutralized by the chitosan, apparently a sufficient number of positively charged sites had been established to screen some of the nitrate from the negatively charged surfaces. The $d$ spacing $(1.27 \mathrm{~nm})$ of sample $\mathrm{C} 1$ confirmed that a small amount of chitosan polymer was probably intercalated into the interlayer space of the smectite (Figure 3, Table 1).

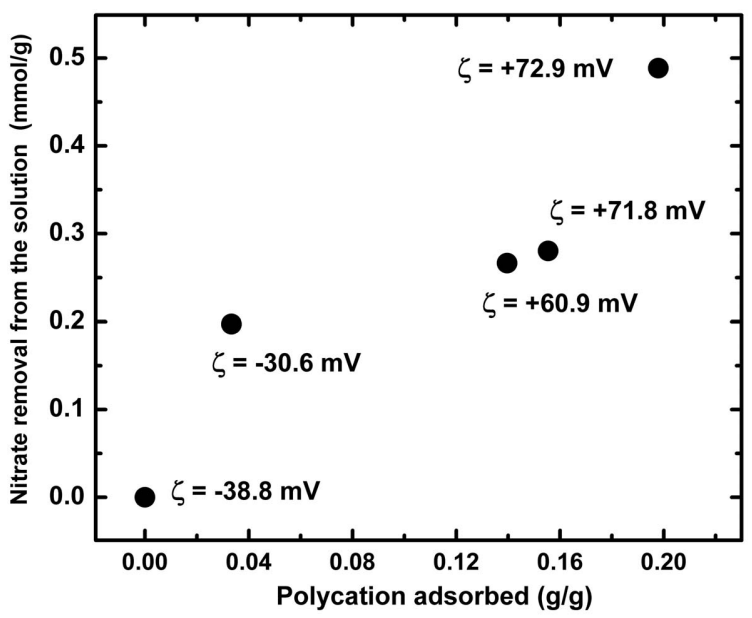

Figure 6. Nitrate $(1.0 \mathrm{mM} \mathrm{NaNO}$ ) removal from solution by reaction with oxidized $\mathrm{CSC}$ samples $(\mathrm{C} 1, \mathrm{C} 2, \mathrm{C} 3$, and $\mathrm{C} 4)$.
Reduced CSC reaction with $\mathrm{NO}_{3}^{-}$

Nitrate removal from solution. When nitrate was reacted with reduced CSC, the amount of nitrate removed from solution (Figure 7) was extensive and followed the same trend with increasing chitosan loading as observed in the oxidized samples (Figure 6, Table 1). While the $\zeta$ potential of the reduced samples was not measured, the fact that nitrate was attracted to them (those with adsorbed polycation) is prima facie evidence that the charge was indeed reversed by the chitosan to levels that approximated those observed in the oxidized samples. No measurable reaction or adsorption was observed between nitrate and reduced sample $\mathrm{C} 0$.

These observations are consistent with the nitrateremoval results of Su et al. (2012) using PSC (Figure 7). The extent of nitrate removal in that study, however, was about half as much as observed in the present study, indicating that chitosan creates a more attractive environment for nitrate removal than does PDADMAC. This is in agreement with the unique anion exchange characteristics of smectite-chitosan composites reported previously (Darder et al., 2005; Bleiman and Mishael, 2010).

Nitrate reduction and $\mathrm{Fe}(\mathrm{II})$ oxidation. Not only was nitrate removed, but the presence of structural Fe(II) in the reduced CSC samples created the possibility that nitrate could be reduced. Solutions were, therefore, analyzed for nitrite and ammonium (two reduction products of nitrate). While no ammonium was detected in the solutions, nitrite was found in all reduced CSC samples except $\mathrm{C} 0$ (Figure 8). As in the case with oxidized $\mathrm{C} 0$, the reduced $\mathrm{C} 0$ had no polycation present to reverse the charge and, thereby, attract nitrate and reduce it.

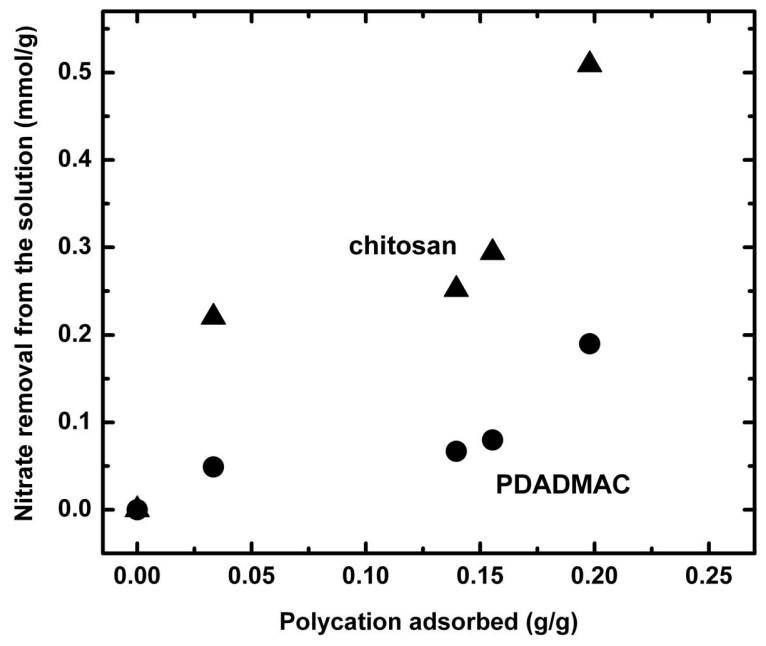

Figure 7. Nitrate $(1.0 \mathrm{mM} \mathrm{NaNO}$ ) removal from solution by reaction with reduced $\mathrm{CSC}(\mathrm{C} 1, \mathrm{C} 2, \mathrm{C} 3$, and $\mathrm{C} 4)$, compared with results from $\mathrm{Su}$ et al. (2012) for the polycation PDADMACSWa-1 composites (PSC) in the reduced state. 


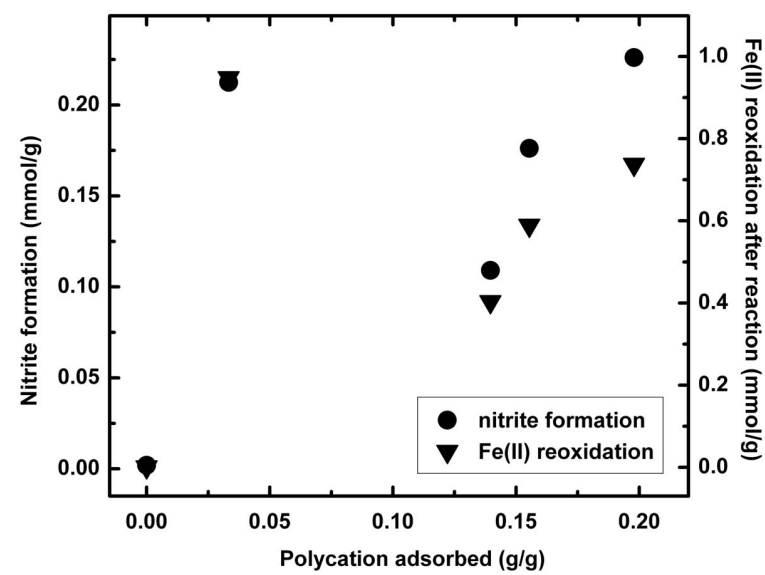

Figure 8. Nitrite formation and $\mathrm{Fe}$ (II) reoxidation as a function of chitosan adsorbed in the CSC samples after reaction with $1.0 \mathrm{mM} \mathrm{NaNO}_{3}$ solution.

The nitrite clearly arose through the chemical reduction of nitrate by structural $\mathrm{Fe}(\mathrm{II})$ (equation 2). This is abundantly evident by plotting the amount of $\mathrm{Fe}(\mathrm{II})$ reoxidized $v s$. the amount of nitrite formed. The two measurements followed each other step by step (Figure 8). In fact, a near-linear correlation was observed (Figure 9), consistent with the hypothesis that a redox reaction between nitrate and structural $\mathrm{Fe}$ had occurred to produce nitrite. A plot of the amount of nitrite in solution $v s$. nitrate adsorbed/exchanged (Figure 10) revealed that $\sim 95 \%$ of the nitrate was reduced to nitrite and released to solution at low loadings, whereas at greater loadings the percentage was closer to $50 \%$.

The slope of the correlation in Figure 9 revealed that the stoichiometry of the reaction was $\sim 4$ moles of $\mathrm{Fe}(\mathrm{II})$ oxidized for each mole of nitrite formed. Equation 2 predicts that the relationship should be $2: 1$ instead of $4: 1$, so the nitrite found in solution does not account for

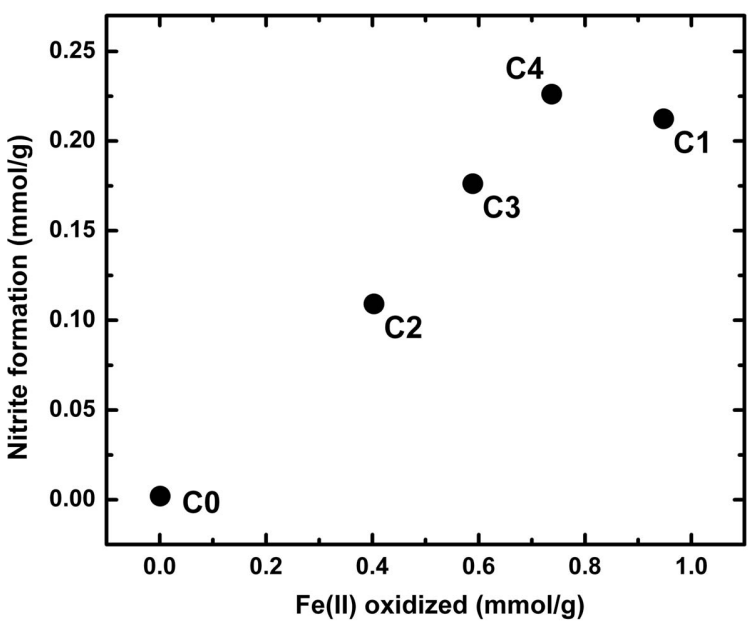

Figure 9. Nitrite formation as a function of $\mathrm{Fe}(\mathrm{II})$ oxidation in reduced $\mathrm{CSC}$ all of the $\mathrm{Fe}$ (II) that was oxidized. No definitive explanation for this seemingly anomalous result was found, but several possibilities were considered.

(1) Perhaps more nitrite was formed than was measured in solution, with the remainder being retained as an adsorbed or exchanged anion on the CSC complex. This explanation is a possibility in samples $\mathrm{C} 2$ to $\mathrm{C} 4$, but sample $\mathrm{C} 1$ does not fit within that hypothesis because almost all of the nitrate adsorbed was found in the form of nitrite in solution (Figure 10); yet, twice as much $\mathrm{Fe}(\mathrm{II})$ was reoxidized than was expected. In the other reduced CSC samples, the solid phase contained abundant sites for anion exchange and adsorption, and would have had the ability to capture some of the nitrite. In fact, adsorbed/ exchanged nitrate may have become reduced in place and the nitrite product held in that same site. Then, if an exchange equilibrium occurred for the nitrite between the solution and solid phases, the amount observed in solution would clearly have been only the fraction determined by the equilibrium constant (which has yet to be well explained). These arguments for CSC samples $\mathrm{C} 2$ to $\mathrm{C} 4$ are not persuasive, however, because such a phenomenon would have increased the observed stoichiometry above 4:1 (i.e. less nitrite being measured in solution than was actually produced), but it remained about the same at 4:1 (Figure 9, Table 1).

(2) Other undetected reduction products may have formed. Among these are ammonium, which, even though not found in solution, could have been retained in the solid phase as an exchanged cation on any exposed smectite surface. Other gaseous reduction products $\left(\mathrm{N}_{2}\right.$, $\mathrm{N}_{2} \mathrm{O}, \mathrm{NO}$ ) may have been produced, but no attempt was made to capture gaseous products for analysis. Again, CSC sample $\mathrm{C} 1$ seems to be inconsistent with this explanation because the amount of nitrite measured accounted for $95 \%$ of the nitrate lost from solution. In

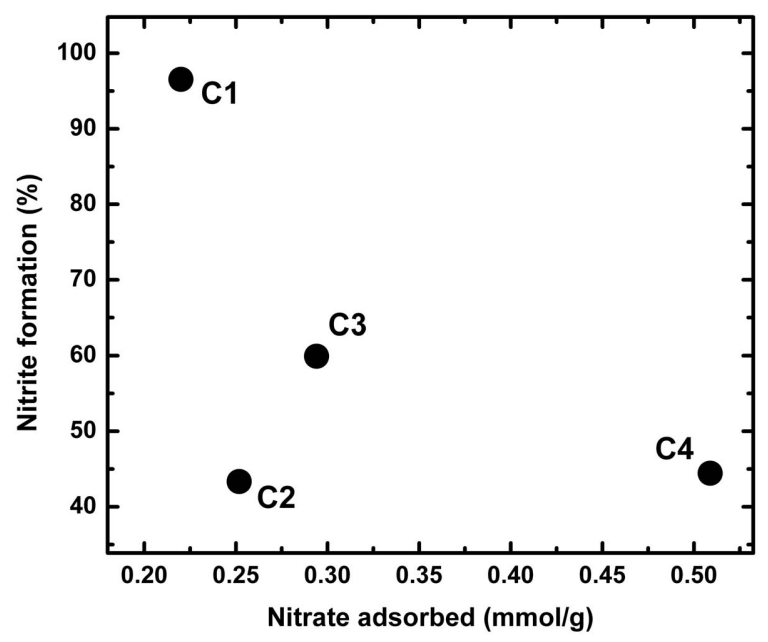

Figure 10. Nitrite in solution (as \% of nitrate adsorbed) as a function of nitrate adsorbed in reduced CSC samples. 
this particular case, the nitrate may have never actually completed the adsorption process before being reduced by the structural Fe(II).

(3) Some reoxidation may have occurred during sample handling due to atmospheric oxygen contamination or some other unidentified oxidant. While this is also a possibility, two factors argue against it. First, a study by Stucki et al. (2014) demonstrated that $<2 \%$ of the total $\mathrm{Fe}$ (II) becomes reoxidized during the handling procedures, and the amount in question here is as much as $15 \%(0.5 \mathrm{mmol} / \mathrm{g})$. This could not account for the $4: 1$ vs. 2:1 difference in Fe:N stoichiometry. Second, one would not expect such oxygen contamination to be so well controlled or so consistent as to preserve the stoichiometric ratio at $\sim 4: 1$. Nevertheless, this possibility is not ruled out.

(4) Another possible explanation is that the reaction is more complex than indicated by equation 2, and involves a three- or four-electron reduction mechanism. Future studies will probe this question more completely, with a view to understanding better the discrepancy in stoichiometry.

Bimodal behavior in reduced CSC. The behavior of reduced $\mathrm{CSC}$ sample $\mathrm{C} 1$ did not fit the same relationship as the other reduced samples, as already mentioned. This is clearly seen in Figures 8-10. The reduced C1 sample contained the smallest amount of chitosan among the four polycation-treated samples, but its nitrite yield $(0.212 \mathrm{mmol} / \mathrm{g} \mathrm{CSC})$ and extent of $\mathrm{Fe}(\mathrm{II})$ reoxidation $(0.936 \mathrm{mmol} / \mathrm{g})$ were approximately the same as in sample $\mathrm{C} 4$, that with the largest amount of chitosan (Figure 8, Table 1). The amount of nitrite formed decreased abruptly between samples $\mathrm{C} 1$ and $\mathrm{C} 2$, then built back up as the polycation loading increased, until in sample $\mathrm{C} 4$ it returned to about the same level as in sample $\mathrm{C} 1$.

In the relationship between nitrite in solution and the amount of Fe(II) reoxidized (Figure 9), sample C1, in spite of being the least loaded with polycation, plotted very near to sample $\mathrm{C} 4$. It also was the most efficient sample for reducing nitrate to nitrite, as indicated by $>95 \%$ of the nitrate lost from solution being converted to nitrite (Figure 10).

This behavior is probably the consequence of the manner in which chitosan interacts with the smectite surfaces and the electron transfer pathway from structural $\mathrm{Fe}$ to the nitrate. This trend was also observed in the case of PDADMAC (Su et al., 2012), and explained in terms of polymer coverage: at low polycation loadings, nitrate adsorption is somewhat promoted by the adsorbed polycation; the low loadings enable optimal electron transfer from uncovered clay surfaces to the adsorbed nitrate, however.

Working hypothesis for the reduction process. The following working hypothesis for the nitrate reduction process was developed (see Figure 11). At low chitosan levels $(0.075 \mathrm{~g} / \mathrm{L})$, the surface of the smectite is populated with islands of polycation monolayers (Figure 11,C1). Nitrate anions are attracted toward these islands and, due to their proximity to the smectite surface as they approach the islands, react with structural $\mathrm{Fe}(\mathrm{II})$ to produce nitrite, perhaps with adsorption being only a transient state. The nitrite is then released back into the surrounding solution according to its equilibrium constant.

As loading levels increase, the polycation forms clusters and/or multi-layer stacks that cover the physical surface more completely, and create more adsorption sites for nitrate from solution (Figure 11,C2). Most of these sites, however, are further from the basal surfaces than at the lower-loading level and are, thus, more shielded from the redox activity at the physical surface and less susceptible to reaction with structural $\mathrm{Fe}$ (II) in the clay layer. In this case, electron transfer also depends more strongly on diffusion or shuttling through the polycation. The complex becomes more heavily populated with adsorbed nitrate anions, and only some of them become reduced. The others remain adsorbed.

The XRD results are also consistent with this hypothesis, which showed that the layers were only partially expanded at low loadings, giving a $d$ spacing of $1.27 \mathrm{~nm}$; whereas at high loadings the $d$ spacing increased to $1.75-1.80 \mathrm{~nm}$, which is consistent with multi-layering of the polycation within the interlayer region (Figure 3, Table 1).

The size and complexity of the polycations introduce uncertainties as to their exact location and total



Figure 11. A schematic diagram of the redox reaction mechanism of nitrate reduction and nitrite generation in the presence of PSC. 
compensating charge. Their presence solely between the superimposed smectite layers has not been confirmed and, in fact, their existence on edge and outer particle surfaces also are indeed probable. Further investigations are needed to confirm a clear description of the polycation configuration and the pathway for electron transfer from structural $\mathrm{Fe}$ (II) to nitrate in solution.

\section{SUMMARY AND CONCLUSIONS}

Results from this study provide clear evidence that the combination of charge reversal and structural $\mathrm{Fe}$ reduction activates smectite surfaces towards nitrate reduction. The linear polysaccharide poly-(D) glucosamine (chitosan) with an acidic $\mathrm{pH}$ of $\sim 3$ effectively increases the positive charge of the smectite surface, and the resulting composites in solution were also slightly acidic ranging from $5.8(\mathrm{C} 1)$ to $4(\mathrm{C} 4)$. Upon addition of the nitrate solution, the $\mathrm{pH}$ remained slightly acidic ranging from 5.5 to 4.7 . The chemically reduced chitosan-smectite composite (CSC) is also highly active toward nitrate reduction, giving a stoichiometry of four moles of $\mathrm{Fe}(\mathrm{II})$ oxidized for each mole of nitrate reduced rather than the expected value of $2: 1$. No conclusive explanation is given for this difference, but further research is needed to understand better the complexities of the redox reaction mechanism and the configuration of the polycation on the clay surfaces. The reductive capacity of the reduced CSC is not linear with chitosan loading, but is high at low loading, drops abruptly, then builds back up as the loading increases. Future studies should pursue the optimum surface coverage by the polycations. These results indicate that clay minerals can be utilized to promote redox reactions with anionic redox-active species as well as those that are cationic.

\section{ACKNOWLEDGMENTS}

The authors acknowledge gratefully financial support of this study by the National Science Foundation, under grants EAR 10-53491 and EAR 11-48459; the Department of the Navy under contract W9126G-12-2-0027; and the Illinois College of Agricultural, Consumer, and Environmental Sciences Office of Research. The authors also express gratitude to Dr Jana Madejová, (Institute of Inorganic Chemistry, Slovak Academy of Sciences, Bratislava, Slovakia) for her excellent FTIR measurements of CSC samples, supported by the Slovak Grant Agency VEGA (grant 2/0132/13).

\section{REFERENCES}

Abugoch, L.E., Tapia, C., Villamán, M.C., Pedram, M.Y., and Dosque, M.D. (2011) Characterization of quinoa protein chitosan blend edible films. Food Hydrocolloids, 25, $879-886$.

Ahn, S.C., Oh, S.-Y., and Cha, D.K. (2008) Enhanced reduction of nitrate by zero-valent iron at elevated temperatures. Journal of Hazardous Materials, 156, 17-22.

Auta, M. and Hameed, B.H. (2014) Chitosan-clay composite as highly effective and low-cost adsorbent for batch and fixedbed adsorption of methylene blue. Chemical Engineering Journal, 237, 352-361.

Bhatnagar, A. and Sillanpää, M. (2009) Applications of chitinand chitosan-derivatives for the detoxification of water and wastewater - a short review. Advances in Colloid and Interface Science, 152, 26-38.

Bhatnagar, A. and Sillanpää, M. (2011) A review of emerging adsorbents for nitrate removal from water. Chemical Engineering Journal, 168, 493-504.

Bhatnagar, A., Kumar, E., and Sillanpää, M. (2010) Nitrate removal from water by nano-alumina: Characterization and sorption studies. Chemical Engineering Journal, 163, 317-323.

Bishop, J., Madejová, J., Komadel, P., and Fröschl, H. (2002) The influence of structural $\mathrm{Fe}, \mathrm{Al}$ and $\mathrm{Mg}$ on the infrared $\mathrm{OH}$ bands in spectra of dioctahedral smectites. Clay Minerals, 37, 607-616.

Bleiman, N. and Mishael, Y.G. (2010) Selenium removal from drinking water by adsorption to chitosan-clay composites and oxides: Batch and columns tests. Journal of Hazardous Materials, 183, 590-595.

Bowen, J.L., Kroeger, K.D., Tomasky, G., Pabich, W.J., Cole, M.L., Carmichael, R.H., and Valiela, I. (2007) A review of land-sea coupling by groundwater discharge of nitrogen to New England estuaries: Mechanisms and effects. Applied Geochemistry, 22, 175-191.

Breen, C. (1999) The characterization and use of polycationexchanged bentonites. Applied Clay Science, 15, 187-219.

Brtáňová, A., Melichová, Z., and Komadel, P. (2012) Sorption of $\mathrm{Cu}^{2+}$ from aqueous solutions by Slovak bentonites. Ceramics - Silikáty, 56, 55-60.

Brtáňová, A., Madejová, J., Bizovská, V., and Komadel, P. (2014) Utilization of near infrared spectroscopy for studying solvation properties of Cu-montmorillonites. Spectrochimica Acta - Part A: Molecular and Biomolecular Spectroscopy, 123, 385-391.

Brugnerotto, J., Lizardi, J., Goycoolea, F.M., Argüelles-Monal, W., Desbrières, J., and Rinaudo, M. (2001) An infrared investigation in relation with chitin and chitosan characterization. Polymer, 42, 3569-3580.

Burow, K.R., Nolan, B.T., Rupert, M.G., and Dubrovsky, N.M. (2010) Nitrate in groundwater of the United States, 19912003. Environmental Science \& Technology, 44, 4988-4997.

Camargo, J.A. and Alonso, A. (2006) Review Article. Ecological and toxicological effects of inorganic nitrogen pollution in aquatic ecosystems: A global assessment. Environment International, 32, 831-849.

Chabani, M., Amrane, A., and Bensmaili, A. (2006) Kinetic modelling of the adsorption of nitrates by ion exchange resin. Chemical Engineering Journal, 125, 111-117.

Cheng, I.F., Muftikian, R., Fernando, Q., and Korte, N. (1997) Reduction of nitrate to ammonia by zero valent iron. Chemosphere, 35, 2689-2695.

Churchman, G.J. (2002) Formation of complexes between bentonite and different cationic polyelectrolytes and their use as sorbents for non-ionic and anionic pollutants. Applied Clay Science, 21, 177-189.

Crini, G. and Badot, P.M. (2008) Application of chitosan, a natural aminopolysaccharide, for dye removal from aqueous solution by adsorption process using batch studies: A review of recent literature. Progress in Polymer Science, 33, $399-447$.

Czímerová, A., Jankovič, L., and Bujdák, J. (2004) Effect of the exchangeable cations on the spectral properties of methylene blue in clay dispersions. Journal of Colloid and Interface Science, 1, 126-132.

Darder, M., Colilla, M., and Ruiz-Hitzky, E. (2005) Chitosan- 
clay nanocomposites: application as electrochemical sensors. Applied Clay Science, 28, 199-208.

Dinu, M.V. and Dragan, E.S. (2010) Evaluation of $\mathrm{Cu}^{2+}, \mathrm{Co}^{2+}$, and $\mathrm{Ni}^{2+}$ ions removal from aqueous solution using a novel chitosan/clinoptilolite composite: Kinetics and isotherms. Chemical Engineering Journal, 160, 157-163.

Dutta, P.K., Duta, J., and Tripathi, V.S. (2004) Chitin and Chitosan: Chemistry, properties and applications. Journal of Scientific and Industrial Research, 63, 20-31.

Ernstsen, V. (1996) Reduction of nitrate by $\mathrm{Fe}^{2+}$ in clay minerals. Clays and Clay Minerals, 44, 599-608.

Ernstsen, V., Gates, W.P., and Stucki, J.W. (1998) Microbial reduction of structural iron in clays - A renewable source of reduction capacity. Journal of Environmental Quality, 27, $761-766$.

Farmer, V.C. (1974) The Infrared Spectra of Minerals. Monograph 4, Mineralogical Society, London, $539 \mathrm{pp}$.

Freeze, R.A. and Cherry, J.A. (1979) Groundwater. Prentice Hall, Englewood Cliffs, New Jersey, USA, 604 pp.

Frost, R.L., Kloprogge, J.T., and Ding, Z. (2002) The Garfield and Uley nontronites - An infrared spectroscopic comparison. Spectrochimica Acta - Part A Molecular and Biomolecular Spectroscopy, 58, 1881-1894.

Fu, F. and Wang, Q. (2011) Removal of heavy metal ions from wastewaters: A review. Journal of Environmental Management, 92, 407-418.

Fu, X. and Qutubuddin, S. (2001) Polymer-clay nanocomposites: Exfoliation of organophilic montmorillonite nanolayers in polystyrene. Polymer, 42, 807-813.

Hell, F., Lahnsteiner, J., Frischherz, H., and Baumgartner, G. (1998) Experience with full-scale electrodialysis for nitrate and hardness removal. Desalination, 117, 173-180.

Howarth, R.W. (2008) Coastal nitrogen pollution: A review of sources and trends globally and regionally. Harmful Algae, 8, $14-20$.

Huang, C.P., Wang, H.W., and Chiu, P.C. (1998) Nitrate reduction by metallic iron. Water Research, 32, 2257-2264.

Hwang, Y.H., Kim, D.G., and Shin, H.S. (2011) Mechanism study of nitrate reduction by nano zero-valent iron. Journal of Hazardous Materials, 185, 1513-1521.

Jeon, C. and Park, K.H. (2005) Adsorption and desorption characteristics of mercury (II) ions using aminated chitosan beads. Water Research, 36, 3938-3944.

Khan, S.A., Mulvaney, R.L., and Mulvaney, C.S. (1997) Accelerated diffusion methods for inorganic-nitrogen analysis of soil extracts and water. Soil Science Society of America Journal, 61, 936-942.

Komadel, P. and Stucki, J.W. (1988) Quantitative assay of minerals for $\mathrm{Fe}^{2+}$ and $\mathrm{Fe}^{3+}$ using 1,10-phenanthroline: III. A rapid photochemical method. Clays and Clay Minerals, 36, $379-381$

Korom, S.F. (1992) Natural denitrification in the saturated zone: A review. Water Resources Research, 28, 1657-1668.

Kumar, M. and Chakraborty, S. (2006) Chemical denitrification of water by zero-valent magnesium powder. Journal of Hazardous Materials, 135, 112-121.

Kumirska, J., Czerwicka, M., Kaczyński, Z., Bychowska, A., Brzozowski, K., Thöming, J., and Stepnowski, P. (2010) Application of spectroscopic methods for structural analysis of Chitin and Chitosan. Marine Drugs, 8, 1567-1636.

Liu, H., Guo, M., and Zhang, Y. (2014) Nitrate removal by $\mathrm{Fe}^{0} / \mathrm{Pd} / \mathrm{Cu}$ nano-composite in groundwater. Environmental Technology, 35, 917-924.

Manceau, A., Lanson, B., Drits, V.A., Chateigner, D., Gates, W.P., Wu, J., Huo, D., and Stucki, J.W. (2000) Oxidationreduction mechanism of iron in dioctahedral smectites: I. Crystal chemistry of oxidized reference nontronites. American Mineralogist, 85, 133-152.

Madejová, J. (2003) FTIR techniques in clay mineral studies.
Vibrational Spectroscopy, 31, 1-10.

Madejová, J. and Komadel, P. (2001) Baseline studies of the Clay Mineral Society Source Clays: Infrared methods. Clays and Clay Minerals, 49, 410-432.

Madejová, J., Pentrák, M., Pálková, H., and Komadel, P. (2009a) Near-infrared spectroscopy: A powerful tool in studies of acid treated clay minerals. Vibrational Spectroscopy, 49, 211-218.

Madejová, J., Pálková, H., Pentrák, M., and Komadel, P. (2009b) Near-infrared spectroscopic analysis of acid-treated organo-clays. Clays and Clay Minerals, 57, 392-403.

Madejová, J., Jankovič, L., Pentrák, M., and Komadel, P. (2011) Benefits of near-infrared spectroscopy for characterization of selected organo-montmorillonites. Vibrational Spectroscopy, 57, 8-14.

Miretzky, P. and Cirelli, A.F. (2009) $\mathrm{Hg}$ (II) removal from water by chitosan and chitosan derivatives: A review. Journal of Hazardous Materials, 167, 10-23.

Monier, M., Ayad, D.M., Weia, Y., and Sarhanb, A.A. (2010) Immobilization of horseradish peroxidase on modified chitosan beads. International Journal of Biological Macromolecules, 46, 324-330.

Mucha, M. and Pawlak, A. (2002) Complex study of chitosan degradability. Polimery, 47, 509-516.

Mulvaney, R.L., Khan, S.A., Stevens, W.B., and Mulvaney, C.S. (1997) Improved diffusion methods for determination of inorganic nitrogen in soil extracts and water. Biology and Fertility of Soils, 24, 413-420.

Ngah, W.W.S., Teong, L.C., and Hanafiah, M.A.K.M. (2011) Adsorption of dyes and heavy metal ions by chitosan composites: A review. Carbohydrate Polymers, 83, $1446-1456$

Osman, Z. and Arof, A.K. (2003) FTIR studies of chitosan acetate based polymer electrolytes. Electrochimica Acta, 48, 993-999.

Öztürk, N. and Bektaş, T.E. (2004) Nitrate removal from aqueous solution by adsorption onto various materials. Journal of Hazardous Materials, 112, 155-162.

Pálková, H., Madejová, J., and Komadel, P. (2009) The effect of layer charge and exchangeable cations on sorption of biphenyl on montmorillonites. Central European Journal of Chemistry, 7, 494-504.

Pálková, H., Jankovič, L., Zimowska, M., and Madejová, J. (2011) Alterations of the surface and morphology of tetraalkyl-ammonium modified montmorillonites upon acid treatment. Journal of Colloid and Interface Science, 363, $213-222$.

Paulino, A.T., Simionato, J.I., Garcia, J.C., and Nozaki, J. (2006) Characterization of chitosan and chitin produced from silkworm chrysalides. Carbohydrate Polymers, 64, 98-103.

Pawlak, A. and Mucha, M. (2003) Thermogravimetric and FTIR studies of chitosan blends. Thermochimica Acta, 396, $153-166$.

Pentrák, M., Bizovská, V., and Madejová, J. (2012) Near-IR study of water adsorption on acid-treated montmorillonite. Vibrational Spectroscopy, 63, 360-366.

Pentrák, M., Pentráková, L., and Stucki, J.W. (2013) Iron and manganese reduction-oxidation. Pp. 701-722 in: Methods in Biogeochemistry of Wetlands (R.D. DeLaune, K.R. Reddy, C.J. Richardson, and J.P. Megonigal, editors). SSSA Book Series, 10, Soil Science Society of America, Madison, Wisconsin, USA.

Pintar, A., Batista, J., and Levec, J. (2001) Catalytic denitrification: direct and indirect removal of nitrates from potable water. Catalysis Today, 66, 503-510.

Prakash, N., Latha, S., Sudha, P.N., and Renganathan, N.G. (2013) Influence of clay on the adsorption of heavy metals like copper and cadmium on chitosan. Environmental 
Science \& Pollution Research, 20, 925-938.

Rabalais, N.N. (2002) Nitrogen in aquatic ecosystems. Ambio, 31, $102-112$.

Radian, A. and Mishael, Y.G. (2008) Characterizing and designing polycation-clay nanocomposites as a basis for imazapyr controlled release formulations. Environmental Science \& Technology, 42, 1511-1516.

Rinaudo, M. (2006) Chitin and chitosan: Properties and applications. Progress in Polymer Science, 31, 603-632.

Samatya, S., Kabay, N., Yüksel, U., Arda, M., and Yüksel M. (2006) Removal of nitrate from aqueous solution by nitrate selective ion exchange resins. Reactive and Functional Polymers, 66, 1206-1214.

Schoeman, J.J. and Steyn, A. (2003) Nitrate removal with reverse osmosis in a rural area in South Africa. Desalination, 155, 15-26.

Seitzinger, S.P. (1988) Denitrification in freshwater and coastal marine ecosystems: Ecological and geochemical significance. Limnology and Oceanography, 33, 702-724.

Soares, M.I.M. (2000) Biological denitrification of groundwater. Water Air and Soil Pollution, 123, 183-193.

Sohn, K., Kang, S.W., Ahn, S., Woo, M., and Yang, S.K. (2006) $\mathrm{Fe}(0)$ nanoparticles for nitrate reduction: Stability, reactivity and transformation. Environmental Science \& Technology, 40, 5514-5519.

Stucki, J.W. (2013) Properties and behavior of iron in clay minerals. Pp. 559-611 in: Handbook of Clay Science (F. Bergaya and G. Lagaly, editors). Developments in Clay Science, 5A, Elsevier, Amsterdam.

Stucki, J.W. and Kostka, J.E. (2006) Microbial reduction of iron in smectite. Comptes Rendus Geoscience, 338, $468-475$

Stucki, J.W., Komadel, P., and Wilkinson, H.T. (1987) Microbial reduction of structural iron(III) in smectites: Soil Science Society of America Journal, 51, 1663-1665.

Stucki, J.W., Goodman, B.A., and Schwertmann, U. (1988) Iron in Soils and Clay Minerals. D. Reidel, Dordrecht, The Netherlands, 980 pp.

Stucki, J.W., Gan, H., and Wilkinson, H.T (1992) Effects of microorganisms on phyllosilicate properties and behavior. Pp. 227-254 in: Advances in Soil Science (R.J. Wagenet, P. Baveye, and B.A. Stewart, editors). Lewis Publishers, Boca Raton, Florida, USA.

Stucki, J.W., Lee, K., Goodman, B.A., and Kostka, J.E. (2007) Effects of in situ biostimulation on iron mineral speciation in a sub-surface soil. Geochimica et Cosmochimica Acta, 71, $835-843$.

Stucki, J.W., Su, K., Pentráková, L., and Pentrák, M. (2014) Methods for handling redox-sensitive smectite dispersions. Clay Minerals, 49, 359-377.

Su, K., Radian, A., Mishael, Y., Yang, L., and Stucki, J.W. (2012) Nitrate reduction by redox-activated, polydiallyldimethylammonium-exchanged ferruginous smectite. Clays and Clay Minerals, 60, 464-472.

Thomson, T.S. (2001) Nitrate concentration in private rural drinking water supplies in Saskatchewan, Canada. Bulletin of Environmental Contamination and Toxicology, 66, $64-70$.

Usuki, A., Kawasumi, M., Kojima, Y., Okada, A., Kurauchi, T., and Kamigaito, O. (1993) Swelling behavior of montmorillonite cation exchanged for $\omega$-amino acids by E-caprolactam. Journal of Materials Research, 8, $1174-1178$

Ward, M.H., de Kok, T.M., Levallois, P., Brender, J., Gulis, G., Nolan, B.T., and Van Derslice, J. (2005) Workgroup report: drinking-water nitrate and recent health findings and research needs. Environmental Health Perspectives, 113, $1607-1614$

Westerhoff, P. (2003) Reduction of nitrate, bromate and chlorate by zero valent iron $(\mathrm{Fe}-0)$. Journal of Environmental Engineering - ASCE, 129, 10-16.

Xue, H., He, H., Zhu, J., and Yuan, P. (2007) FTIR investigation of CTAB-Al-montmorillonite complexes. Spectrochimica Acta A, 67, 1030-1036.

Yan, L.B. and Stucki, J.W. (2000) Structural perturbations in the solid-water interface of the redox transformed nontronite. Journal of Colloid and Interface Science, 225, 429-439.

Yan, L., Roth, C.B., and Low, P.F. (1996) Changes in the Si-O vibrations of smectite layers accompanying the sorption of interlayer water. Langmuir, 12, 4421-4429.

Zadaka, D., Radian, A., and Mishael, Y.G. (2010) Applying zeta potential measurements to characterize the adsorption on montmorillonite of organic cations as monomers, micelles, or polymers. Journal of Colloid and Interface Science, 352, 171-177.

(Received 19 July 2014; revised 6 January 2015; Ms. 900; AE: R. Dohrmann) 